\title{
Becoming Part of the Furniture: The Institutionalization of Information Systems
}

\author{
L. Silva \\ Department of Information Systems \\ London School of Economics and Political Science \\ London WC2A 2AE, England \\ Tel: 1719557641 \\ Fax: 1719557385 \\ E-mail:L.Silva@lse.ac.uk
}

\section{J. Backhouse}

Department of Information Systems

London School of Economics and Political Science

London WC2A 2AE, England

Tel: $\quad 1719557641$

Fax: 1719557385

E-mail: J.P.Backhouse@lse.ac.uk

\begin{abstract}
The institutionalization of information systems allows managers in organizations to concentrate on and devote creative energy to their prime tasks. This paper argues that the process of deciding whether an information system is institutionalized or not can be understood better by examining its political dimension. We focus on the failure to institutionalize the London Ambulance Service information system. Our analysis unravels the political factors that influenced the system breakdown and its abandonment. In doing so, we propose a framework grounded on the interpretive
\end{abstract}


tradition of research into information systems. The framework we are introducing will contribute to the understanding of power and institutionalization, in research into organizational information systems.

\section{INTRODUCTION}

In The Prince, Machiavelli asserts that fortune controls half of our actions, but that we can control the other half. We steer the ship of our lives in the sea of fortune. In steering our lives, we face the problem of distinguishing where the ship finishes and where the sea starts. In other words, how can we know which part of our lives we control and which we do not? There is no point in wasting effort trying to change factors that do not depend on us. It is better to identify them and then to prepare so their effects can be minimized. However, there is a point in putting effort into changing or influencing those factors that do depend on us. Organizations face similar problems when they try to introduce information systems: they want to know what they can do to stabilize an information system. Likewise, organizations would like to anticipate and be ready for those factors that can influence information systems but which organizations do not control.

The stabilization of an information system is its institutionalization. We can say that information systems become institutionalized when they are no longer considered as innovations but as unnoticed and unremarkable tools that people take for granted in doing their work. Institutionalized information systems are noticed only when they break down. An interesting question is, therefore, what makes an information system institutionalized? The institutionalization of information systems can be studied as the outcome of power relations, which may favor or hinder institutionalization. The purpose of this paper is to discuss how power relations hindered the institutionalization of a particular information system.

We propose a theoretical framework that presents the institutionalization of an information system as the outcome of power relations. The framework itself differentiates those relations that can be influenced by agents from those that can not. We illustrate the application of the framework by discussing the case of the collapse of the London Ambulance Service (LAS). In the discussion of this case, we highlight the power aspects that influenced the disaster of the LAS information system, such as the dominant strategies, the differences between managers and trade unions, and the inadequacies of the interpretation of the tasks performed by some of the LAS workers. The LAS case study, as the empirical data for this paper, illustrates the benefits of examining secondary sources as research material.

The study of the process of institutionalization of information systems is relevant for managers and practitioners. The benefits for managers of organizations are evident. If an information system becomes institutionalized, less effort is needed to manage it. Knowledge about the power base of the organization will also ease the management of change. Information systems analysts will also find it useful to know 
the power relations prevailing in the organization, because in this way they can design information systems not only according to users' requirements but also to users' interests. The framework we introduce might also be useful for researchers interested in the processes of institutionalization itself and the political aspects of information systems. It is widely accepted that information systems are social systems, and there is no doubt that studying how they become institutionalized, and also how they do not, should lead us to focus on those aspects that transform information systems from being innovations to being taken for granted as tools of work, which is what organizations and managers want them to be. The framework we propose could provide a starting point for those interested in researching organizational aspects of information systems such as legitimation, control, and politics. Moreover, we believe that qualitative research in information systems should be led by theories grounded in interpretive and phenomenological premises to make sense and to be consistent. The theoretical framework we are proposing in this paper has its roots in phenomenology. Because of that, we believe it will be consistent with qualitative and interpretive research in information systems.

The first section introduces the background of our proposal. Mainly, we discuss the relevant literature of power and information systems and introduce our conceptions on institutionalization. The second section explains our concept of power and introduces the framework, while in the third section we present the analysis of the LAS case. Finally the fourth section presents our conclusions. We hope that our focus on how information systems become institutionalized can help us in understanding what elements are susceptible to alteration, and therefore what we can change or manage, and what elements are independent.

\section{BACKGROUND}

The purpose of this paper is to propose a theoretical framework to explain the institutionalization of information systems. Our proposal considers that by focusing on the power phenomena linked to information systems we can understand the process of their institutionalization. In this section, we will introduce our stance regarding institutionalization in the context of organizations. We then discuss some ideas on power stemming from the social sciences that have influenced research on the political dimension of information systems.

\subsection{Organizational Institutionalization}

Institutionalization is the reciprocal typification of habitualized actions. Institutionalization is constituted by habits. Habits narrow the scope of choices; this constitutes a psychological gain. Institutionalized habits provide a stable background in which actions are often performed with a minimum of effort in decision making. Institu- 
tionalization frees energy that can be channeled to other areas. Institutionalization of information systems will open for managers of information systems opportunities for innovations in other areas (Berger and Luckman 1967). However desirable the state of institutionalization it cannot be created overnight. Institutions have a history, and it is the role of a researcher of information systems to understand and explain the process of institutionalization. We argue that institutionalization of information systems can be understood from a power perspective because institutions control and facilitate actions. In organizations, the institutionalization of an innovation, and in this case of an information system, will require effort and deployment of resources.

The process of institutionalization has been central for some researchers of organizational studies. According to Clegg (1990), there are two streams in the institutional school of organization studies, one from the east coast of the US, and the other from the west coast. Meyer and Rowan (1991), who are from the west, concentrate on the processes that lead to the institutionalization of rules, how they are brought into being, and particularly how they become legitimate. They follow the phenomenological approach to institutions of Berger and Luckman. DiMaggio and Powell $(1983,1991)$ in the east concentrate on how organizations structure themselves by taking elements from the environment; that is, how organizations adopt innovations and how to explain similarities among organizations. Although studying how organizations adopt information systems is an interesting topic, in this paper we will follow the west coast stream mainly for two reasons. First, because having phenomenology as its ontological stance, it makes it more suitable for interpretive and qualitative research; and second, because the focus of our research is on how information systems become legitimate and institutionalized within organizations.

\subsection{Power and Information Systems}

The study of power has been central in social and political sciences. Thus, almost every sociologist, anthropologist, or political scientist has her or his own view of power. However, we will discuss the dominant debate between voluntaristic and deterministic conceptions of power and the proposals to resolve this debate. We will briefly discuss the work of Lukes, Foucault, Giddens, Habermas, Latour, Callon and Law because they have influenced research on power and information systems. An exhaustive discussion of this debate is beyond the scope of this paper (for a more detailed discussion, see Clegg [1989] and Law [1991a]).

The voluntaristic approach to power in social sciences is exemplified by Lukes (1974). He focuses on the exercise of power and the interest of the individual. Thus, A is exercising power over B when A is affecting B against B's interests. This approach, although insightful, leads to the epistemological problem of how to determine interests without encroaching moral relativism. It is important to notice that voluntaristic approaches explain power adopting mechanical metaphors, such as one individual or group affecting directly other individuals or groups (see Clegg 1989). This conception of power is visible in some research in information systems, particu- 
larly the research focused on the politics of implementation such as Keen (1981) and Markus (1983). Markus and Bjørn-Andersen (1987) have based their work on Lukes in proposing a framework for the analysis of power exercised by information systems professionals over users.

In addition to the voluntaristic approach that focuses on agency for the exercise of power, other researchers have focused on how social structures exercise power. Perhaps one of the most influential social scientists moving from the agency and sovereign view of power is Foucault, who has abandoned mechanistic models of power. He has developed two concepts regarding power. First, Foucault (1972, 1980), in considering the relationship between power and knowledge, studied how knowledge is constructed, how it enacts domination and particularly how subjects take it as truth. Second, Foucualt (1977) developed the concept of disciplinary power, power depending upon surveillance. Administrative authorities carry out surveillance activities by collecting and holding information about society, its members and their actions. In organizational life, disciplinary power becomes associated with attempts to regularize activities in time and space. The latter concept has guided research on power and information systems, particularly that of Zuboff (1988) and Sewell and Wilkinson (1992), who have focused on how information systems can become instruments for exercising disciplinary power. he concept of power knowledge, on the other hand, is examined by Bloomfield and Coombs (1992) in mentioning how computer sciences have affected the way managers estimate the capabilities of information systems. The concepts of power and knowledge in Foucault's work and our view of institutionalization are not far from each other. This is because we aim at explaining the process of how an information system becomes objectivized and takenfor-granted knowledge.

Another significant set of ideas on power is in critical theory, which seeks emancipation from ideology. Habermas $(1970,1972,1979)$, one of the critical theoreticians, argues that power distorts communication and therefore it hinders emancipation. Critical theory's focus on communication and power has made it an attractive theoretical ground for research in information systems. Habermas's influence is manifest in the works of Scandinavian researchers who have focused on how information systems can be instruments of emancipation (Bjerknes, Ehn and Kyng 1987; Bodker et al. 1987; Ehn and Kyng 1987; Friedman and and Cornford 1987). Hirschheim and Klein (1994) have modified an information systems methodology to achieve emancipation in the organization. Empowerment, as the result of implementing information systems, is the concern of Bloomfield and McLean (1995). However, their focus is still in the realm of information systems design and not on how they become institutionalized. We are not implying that research on the political features of implementation and design of information systems is irrelevant. On the contrary, we believe that our research is complementary to these efforts, because it is difficult to institutionalize a poorly designed information system or one whose implementation has been badly managed. 
Giddens $(1979,1984)$ has offered a theory to solve the debate between structure and agency in proposing the concept of the duality of structure, which is a dialectical relation between agency and structure. The duality of structure explains how agents when acting draw on structures that can be of domination, interpretation or legitimation. Giddens' insights have been applied to the field of information systems by Walsham (1993) and Orlikowski and Robey (1991). Walsham argues for looking at how context and social process influence each other in analyzing the organizational impact of information systems. One of Walsham's contributions is to propose a framework based on structuration theory that explains the dialectical relation between information systems and organizations. Orlikowski and Robey introduced a concept of the duality of technology that recognizes the facilitative and constraining characteristics of information technology. They discuss the institutionalization of a productive tool for developing software but do not discuss fully the political factors that influence that institutionalization. The contributions of Walsham and of Orlikowski and Robey go beyond the relationship between analysts and users and the implementation of information systems. They offer a richer picture of the organizational impact of information systems by taking into account the dialectical relation between actions and structures.

Monteiro and Hanseth (1995) recognized the contributions of Orlikowski and Robey and of Walsham but at the same time point out the limitations of their scope. Structuration theory and the duality of technology do not account for the influence of social aspects on the design of technology. Monteiro and Hanseth maintain that neither Orlikowski and Robey nor Walsham describe the influence of social factors in the information systems they studied. For example, these applications of structuration theory do not lead to identifying how interests are inscribed in information systems and how technology makes social relations stable. To do so, Monteiro and Hanseth drew on actor network theory to explain the development of information infrastructures and the diffusion of standards. Their work comes close to explaining the institutionalization of information systems, although they do not focus on the political elements.

Actor network theory focuses on the relationships among science, society and technology (Law 1986, 1991b: Latour 1991; Callon 1991; Akrich 1992; Akrich and Latour 1992). One of the main premises of actor network theory is considering the social and the technical world at the same level. According to Callon (1986, p. 224),

Translation is the mechanism by which the social and natural worlds progressively take form. The result is a situation when certain entities control others. Understanding what sociologists generally call power relationships means describing the way in which actors are defined, associated and simultaneously obliged to remain faithful to their alliances.

Actor network theoreticians subscribe to three epistemological axioms. First, the agnosticism of the observer that means that the observer avoids censoring and making ethical or moral judgements regarding the protagonists of their object of study. The second principle is the one of symmetry. This consists of describing scientific and 
technological issues in the same terms. The third principle is about free association. This implies abandoning all $a$ priori differences between social and technological events. Actor network theory constitutes an alternative to dual conceptions of technology and society. As well as Monteiro and Hanseth, Vidgen and McMaster (1995) have applied the concepts of actor network theory, particularly from Latour (1987). These authors drew on Latour's ideas to check the limitations of other frameworks, such as the dualism of technology and society, to understand how information systems become black boxes in an organization. We associate the concept of information systems becoming black boxes with their institutionalizations. Bloomfield and Danieli (1995) have used concepts of actor network theory to analyze the exercise of power of information technology consultants over their customers. Sociology of translation is applied by Bloomfield and Best (1992) for analyzing power exercises during the development and implementation of information systems. This work is enlightening in the sense that one sees the political processes and political resources deployed by information systems consultants to exercise power over their customers. Power is a concept with many approaches and theories in social sciences, and it is our belief that some of these theories are not mutually exclusive but complementary. The circuits of power framework that we propose in this paper are an attempt to integrate the contributions that many social scientists have made in the study of power.

\section{THE CIRCUITS OF POWER FRAMEWORK}

In his book Frameworks of Power, Clegg (1989) carefully analyzes how social science has considered the concept of power. He discusses different frameworks and concepts to introduce his framework of circuits of power, which he claims includes most of the insights proposed by previous social scientists. Clegg argues that power is a relational concept. Hence, power is something that cannot be owned, and its exercise will depend on relations. Clegg uses the circuits metaphor to emphasize the relational nature of power. For him, social relations sustain, maintain, or transform power. The starting point for Clegg in analyzing power relations is the organization. The application of the circuit framework should lead us then to understand the relationship between the authority and politics of organizations. The circuits framework considers power as circulating in three different circuits: the episodic circuit, the social integration circuit, and the system integration circuit. The three circuits are linked by obligatory passage points (OPPs).

The three circuits of power represent three types of power. Clegg formulates these to move away from Lukes' three dimensional notion of power. The episodic circuit represents causal power which is the most apparent and most evident of the types of power (see Figure 1). Clegg derives his notion of episodic power from Dahl (1957). Dahl considers that A is exercising power over B when A gets B to do something B 
would not otherwise do. ${ }^{1}$ However, Clegg maintains that A would not be able to exercise power over B if the standing conditions, which are constituted by resources, were not favorable to A (see Figure 1). The standing conditions are determined by the extant rules of meaning and membership that constitute the identity and position of the agencies in the organization. These rules of meaning and membership constitute the circuit of social integration and, without it, the understanding of episodic power would be incomplete. The third circuit, the circuit of system integration, carries facilitative power. This notion suggests that when A gets B to do something B would not otherwise do, A's power is facilitative because A is able to set and achieve collective goals. The focus of this circuit is domination because it concerns how agents comply with their duties in order to achieve collective goals. Clegg suggests that compliance is achieved by techniques of discipline and production. If successful, these techniques in the long term will become stable institutional fields or, as Clegg himself calls them, actor-networks. In this section we discuss each of the elements of the circuits framework.

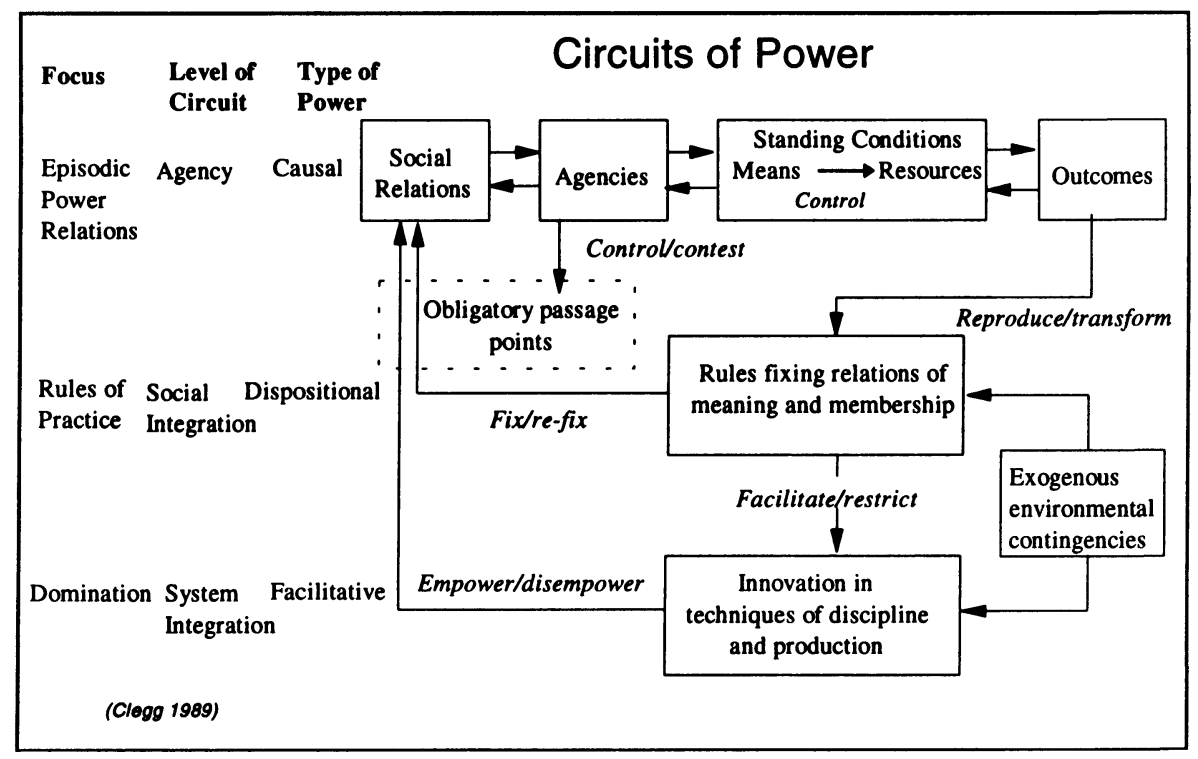

Figure 1 The Circuits of Power.

'This type of power is also known as "power over" (Law 1991) because A is exercising power over B. 


\subsection{Outcomes of the Circuits}

Organizational information systems are constituted by different and heterogeneous elements. These elements could be tangibles like computers, telephones and printers. They can also be people, either managers or users, as well as procedures and knowledge associated with the tasks performed by the information system. An institutionalized information system will become a black box, in the sense that all its members and stakeholders may not notice how it operates. Most actions regarding an institutionalized information system will become predictable. Users will operate the system by applying knowledge that they take for granted, in the same way people use telephones and radios in the office. An institutionalized information system will be noticed only when it breaks down. To be institutionalized, all procedures and activities related to the information system should become a habit. Actions will be typified; this means that those performing the actions will play a role defined by the nature of the activities.

What is important is that most of the skills and the knowledge required to operate the information system will be made objective and external so they can be transferred to those who will eventually play the roles. Clearly institutionalized procedures and tasks in organizations are performed by roles and not by individuals, in the sense that whenever an individual leaves, the role can be filled smoothly. In our case study, the way the information system affected the performance of tasks in the organization will be analyzed when considering the circuit of social integration. Furthermore, any information system to become institutionalized will have to be legitimate. If the new practices or technology associated with the information system become illegitimate, then institutionalization will not occur. The legitimation of the information system will depend on the social integration circuit. The episodic circuit of power indicates that only those agents controlling resources will be able to achieve their desired objectives. However, the circuits of power diagram demonstrates that, in order to achieve their goals, those agents need to have fixed the relationship between the circuits of social and system integration. The fixing of these circuits will become an actor network, or an obligatory passage point. Obligatory passage points are constituted by cohesively connected roles with technical and social agents. The important implication here is that only those information systems resulting from the fixed circuits will become institutionalized. This is because the outcome of the circuits the information system - will have an impact in the whole organizations. If an information system is not fixed as an obligatory passage point, its institutionalization will not be achieved, as it is illustrated in the LAS case study. 


\subsection{The Episodic Circuit of Power}

This is the most evident of the circuits of power because it leads directly to tangible outcomes. Power is manifested here by agents ${ }^{2}$ being capable of controlling resources and establishing alliances to produce their intended outcomes. Agencies and resources are its main elements. It is in this circuit where agents struggle to control resources. The arrows pointing to the right stand for agents acting to achieve their desired outcomes, while arrows in the opposite direction denote resistance. Those agents who successfully control resources will be those with a stronger power base: this is what the standing conditions represent in the figure. The power base of agents is given by the circuits of social and system integration that will be the focus of the following sections.

We have learned from Foucault that the outcome of any exercise of power will be actions. Developers and designers should, as the first step toward understanding power, identify and describe the intended outcomes of the information system in terms of actions. It is important to identify those actors who would execute the outcome, as well as those who would benefit. Finally, the analysis of the circuit will be complete when the resources required to carry out the outcomes are identified.

Organizations that succeed in implementing information systems are those able to arrange their circuits of power in such a way that agents will be capable of achieving their projected outcomes. We believe that looking exclusively at the circuit of episodic power is not enough to understand how organizations achieve this desirable state. Information systems will affect organizations in two ways. Information systems will affect the way jobs are performed, and they are going to change organizational norms, meanings, and membership of groups. The former concerns the circuit of system integration and the latter the circuit of social integration. Furthermore, change in either of the circuits of social or system integration should be fixed in obligatory passage points, which will be discussed in a later section.

\subsection{The Circuit of Social Integration}

Clegg (1989) defines social integration in terms of the relation between rules of meaning and membership. The analysis of this circuit will identify the legitimate (formal rules) and illegitimate (informal rules) dimensions of power within the organization. The recognition of the illegitimate dimension of power, or its dark side (Hirschheim and Klein 1994), is fundamental in performing a complete political appraisal of the organization. ${ }^{3}$

${ }^{2}$ Agency here does not only refer to human beings. Agents can be groups, organizations, animals, or machines (Clegg 1989).

${ }^{3}$ Mintzberg (1983) gives a negative connotation to the informal dimension of power. He refers to it as politics or illegitimate power. This moral position might hinder the objectivity of researchers or system analysts. 
One of the reasons why information systems do not achieve their goals is the lack of fit between the new meanings arising from the new information system and the prevailing organizational rules and norms. In any organization, tension will arise as a consequence of the "lack of fit" between the institutional order and its material condition. The material condition is constituted by technology, techniques, and methods of production, whereas the core institutional order will be integrated by the values, beliefs, and norms already institutionalized in the organization. The lack of fit will be characterized by a type of strain stemming from the incompatibility between the institutional order and the material base (Lockwood 1964). In the case of this lack of fit, the material conditions, according to Lockwood, will engender social relationships and practices that can threaten the organization. The consolidation of these social relationships and practices will depend on the success with which managers are able to cope with the disintegrating tendencies within the organization. The circuit of social integration comprises the norms, rules, and meanings that give identity to particular groups and allow their integration. In other words, this circuit comprises what Lockwood called the core institutional order. The realization of this circuit will allow analysts and developers to incorporate in the system those characteristics required to make it fit in the organization.

\subsection{The Circuit of System Integration}

In the organizational context, system integration is the technological means of control over the material and social setting and the skills associated with these means (Lockwood 1964). Besides the material means of production, Lockwood includes in system integration the material means of surveillance. In short, we might say that system integration is constituted by techniques of production and discipline. System integration deals with facilitative power because the material conditions of production might empower or disempower agencies in their productive activities. The circuit of system integration is the major source of change in the circuits of power framework, particularly when the material conditions of production are altered; hence its relevance to our study. Changes in the circuit of system integration will entail new agencies, techniques and practices that the circuit of social integration might find difficult to resolve. That is why the introduction of computer-based information systems, insofar as they transform the circuit of system integration, will always be contentious. Success in implementation will depend greatly on the managerial ability to translate the new rules and norms implied by the system into pieces of discourse that other members of the organization can understand and accept. This could explain why participative methods for developing information systems might overcome implementation resistance more easily than other methods. User participation can be understood as a process through which the translation of the new rules and meanings is accomplished during the design and development stages of the system and not at the moment of implementation. In this way, participative methodologies integrate user interests and meanings to the system during its design and development. 
The circuit of system integration is fundamental for understanding power relationships in information systems, not only because it provides an analytical tool for the way technology affects power relations, but also because it helps us to understand the way information systems can be shaped by power. To identify this circuit, analysts should focus on how information systems will be used as means of production, control, and discipline.

\subsection{Obligatory Passage Points (OPPs)}

Although this term might sound strange, this is the crux of the circuits of power. Whenever an innovation is introduced in organizations, it creates new meanings, and therefore disturbs the circuit of social integration. The new meanings are fixed in OPPs. An obligatory passage point is an actor network linked by discourses presenting the solution of a problem in terms of resources owned by the agent that proposes the OPP. Obligatory passage points will allow the formation of alliances and the control over resources that agents need to achieve their outcomes.

The concept of obligatory passage points was developed within the "sociology of translation" and actor network theory and developed by the French sociologists Callon and Latour (Callon 1986; Callon, Law and Rip 1986; Latour 1987). These theories attempt to provide a whole picture of power relationships. There are four "moments of translation": problematization, interessment, enrolment and mobilization.

Callon (1986) explains them in detail. The first step is problematization or how to become indispensable. Problematization is when, given a problem, one actor, through rhetorical means, presents the solution of that problem in terms of his or her resources. In this way, one group of actors defines an OPP. Following a successful problematization, the group of actors that experience the problem must be convinced that the only way to resolve their problem is by traversing the OPP. The second translation step is called interessment. After the identities of the actors and OPPs have been defined, the group of actors experiencing the problem must be isolated. This isolation consists of impeding other possible alliances or interference that might challenge the legitimacy of the OPP. If the interessment is successful, it will confirm the validity of the problematization and the alliances. The third translation step is enrolment. During this step, the alliances are consolidated through bargaining and making concessions. The fourth and final step is the mobilization of the allies. This mobilization implies that actors will become spokespersons of the groups they claim to represent. This step consists in determining the legitimacy of the spokesperson. The movement between each step is called displacement, which involves discursive practices. When displacement occurs, power is exercised. Information systems can be viewed as OPPs. For example, some commercial airlines practically force travel agents to use their reservation systems. Those airlines have converted their information systems in successful OPPs that travel agents must traverse if they want to sell airplane tickets. 
Actor network theory and obligatory passage points have been the centre of criticism by sociologists of knowledge (see Collins and Yearley 1992a, 1992b; Callon and Latour 1992). One of the fundamental elements in the Collins and Yearley criticism of actor network theory focuses on the symmetry principle. The principle of symmetry, as discussed above, consists on describing human and non-human actors with the same vocabulary. While Callon and Latour claim that the symmetry principle avoids the ontological trap of reducing nonhuman actors to either natural objects or social constructions, Collins and Yearley suggest that, in actor network descriptions, only language changes but the story remains the same. Moreover, Collins and Yearley maintain that actor network descriptions are conservative and prosaic: conservative because they are limited to descriptions and narratives; prosaic because they lack commonsensical surprises. ${ }^{4}$

Despite their sharp critique, Collins and Yearly (1992a, p. 314) recognize that actor network theory could give an interesting account of the relationship between technology and society. Furthermore, they acknowledge that once actor network theory offers an explanation for non-human actors' behaviour it can contribute "to the detailed analysis of the relations of power between actors and networks (Collins and Yearley 1992b, p. 375). It is precisely because of these two virtues of actor network theory that Clegg introduced it in his circuits framework (see Clegg 1989, pp. 202-207). We believe that Collins and Yearley have a point when they ask actor network theoreticians to give explanations rather than descriptions, especially regarding nonhuman actors. In our case study, particularly when we deal with the failure of the information system, we will bear in mind their request to avoid prosaic descriptions by offering an explanation of the failure.

\section{THE LONDON AMBULANCE SERVICE COMPUTERIZED INFORMATION SYSTEM}

The London Ambulance Service (LAS) was selected as the case study to illustrate the circuits of power framework for various reasons. First, there is consensus about the failure of this information system. This eases our task because we do not need to argue that this was a failure as an information system. Second, the report of the independent inquiry (Page, Williams and Boyd 1993) is a public domain information and there are many reports and analyses about it. However, because our sources were secondary, we should be aware that we are dealing with interpretations of interpreta-

\footnotetext{
${ }^{4}$ Regarding Callon's (1986) paper on the scallops of St. Brieuc Bay, Collins and Yearly ask Callon to explain why the scallops rejected anchoring. Collins and Yearly argue that Callon's description of the scallops' refusal to anchor is not enough to understand why the scallops did not transit the obligatory passage point. It is in this sense that Collins and Yearly claim that anchor network descriptions are conservative and prosaic.
} 
tions. We have been careful in selecting diverse sources to establish some degree of triangulation. In fact, secondary sources for the LAS case allowed us "to pan for gold," as Jarvenpaa (1991) calls it, with very good results.

The analysis of the case study is presented in the form of a narrative. We consider the elements of each circuit. Bearing those in mind, we then discuss what happened to the LAS information system. The idea is to identify all possible elements or factors that could have hindered the institutionalization of the information system. Our aim is not to arrive at a conclusion isolating a unique factor for the noninstitutionalization of the information system but to articulate an explanation covering all the possible political factors. The framework is a set concepts that will help researchers to collect, analyse, and interpret data and practitioners to identify elements and processes that hinder or favour institutionalization.

\subsection{Analysis and Reinterpretation of the Case Study}

During October and November 1992, LAS launched a computer-aided dispatch (CAD) information system. On October 29, news broke that the CAD system had collapsed. As a consequence, twenty people allegedly died (Beynon-Davies 1993). The system was reinstalled, but a week later the system crashed again. Immediately, the system was abandoned totally and manual procedures were again put in place. The chief executive officer of LAS announced his resignation. The British government reacted by ordering an independent inquiry. LAS managers had introduced the CAD system to change the organizational culture and to improve the overall performance of the service (Robinson 1994). This is why the history of the CAD system is relevant to our argument.

The CAD system was introduced in a context of financial and performance problems and poor industrial relations. By the time the CAD system was conceived, in the early 1990s, the British government wanted to transform the National Health Service (NHS) into an internal market. If this transformation were to be successful, the NHS would be characterised by more efficient and competitive services and operations. New management was appointed to LAS in 1990 and was put under pressure to improve performance and reduce costs (Hougham 1995). Information technology and computerized information systems were considered by the new LAS management to be techniques and strategies to solve their problems, and the decision to develop the CAD system was made. Of the bids submitted, the one selected was by System Options. ${ }^{5}$ This company won the $£ 1.1 \mathrm{M}$ contract for the system in June 1991. The offer was substantially below the one presented by IAL, a BT subsidiary, of $£ 7.5 \mathrm{M}$ (Beynon-Davies 1993). Going for the cheapest offer was criticised by the report

${ }^{5}$ This was a small company without previous experience in developing systems of this magnitude. Hougham argues that the lack of experience in project management of this company was one of the main reasons for the collapse of the system. 
inquiry (Page, Williams and Boyd 1993). Nevertheless, if the system had not failed, LAS managers might have been praised for saving public money. In this sense, by selecting the least expensive of the bids, they were doing their job of reducing costs and improving efficiency. Our theory of circuits of power suggests that the adoption of innovations in organizations responds greatly to environmental uncertainties rather than to a rationally based on calculations. Table 1 illustrates the influences of exogenous environmental contingencies on the circuits of social and system integration.

Table 1 Exogenous Contingencies Affecting Social and System Integration.

\begin{tabular}{|c|c|c|}
\hline $\begin{array}{c}\text { Exogenous } \\
\text { Contingencies }\end{array}$ & $\begin{array}{c}\text { System } \\
\text { Integration }\end{array}$ & $\begin{array}{c}\text { Social } \\
\text { Integration }\end{array}$ \\
\hline LAS crisis & $\begin{array}{l}\text { Adoption of techniques } \\
\text { towards cost-effective- } \\
\text { ness }\end{array}$ & $\begin{array}{l}\text { Redundancies and poor } \\
\text { industrial relations }\end{array}$ \\
\hline $\begin{array}{l}\text { Managerial Discourses } \\
\text { Available (strategies } \\
\text { supported by IT) }\end{array}$ & $\begin{array}{l}\text { Redesign of jobs } \\
\text { Managers having more } \\
\text { control over operations; } \\
\text { Employees lose discre- } \\
\text { tion }\end{array}$ & $\begin{array}{l}\text { Uncertainty because of } \\
\text { the new rules } \\
\text { Changing traditional au- } \\
\text { thority structures }\end{array}$ \\
\hline
\end{tabular}

The episodic circuit of power. This circuit focuses on the relationship between resources and outcomes. The new system was expected to improve the performance of the service, to reduce operational costs, and to change the culture of the organization. There were concerns about the quality of the service before the development of the system. A survey conducted by NUPE in 1992 revealed that only $13 \%$ of their members thought that they were providing a good service. The period of time, according to British standards, from the moment an ambulance is requested to the moment it arrives should be approximately fourteen minutes. LAS was far from matching this standard. It was thought by LAS managers that the introduction of a CAD system might produce a more efficient dispatching system that would result eventually in matching the standard. Table 2 presents the main elements in our analysis of the episodic circuit of power. We have highlighted the social relations that give identity to the agencies involved in the circuit of episodic power as well as their standing conditions. The power struggle dynamic between LAS management and staff is depicted in Figure 2. It can be appreciated that, despite having different goals, both agencies had one in common: the improvement of services.

In the context of the CAD system, looking exclusively at the episodic circuit of power gives us a picture where the strong position held by management, based on numerous resources and decision making, should have been enough to produce a successful information system. This assumption is supported by two theories of 
power in organizations: contingency (Hickson et al. 1971); and resource dependency (Pfeffer 1981). Contingency theory considers that power concentrates in centrality, i.e., the capacity of decision making whereas resource dependency theory relates power to control over resources. If managers had financial resources and were in the highest position of decision making, why did they not succeed in implementing the system? What type of power did they lack? It can be argued, using our framework terminology, that the circuits of system and social integration were not fixed in a successful obligatory passage point. These elements are not considered by contingency and resource dependency theories, and they are the main contribution of the circuits of power framework.

Table 2 The Episodic Circuit of Power.

\begin{tabular}{|c|c|c|c|}
\hline \multirow{2}{*}{$\begin{array}{c}\text { Social } \\
\text { Relations }\end{array}$} & \multirow[b]{2}{*}{ Agencies } & \multicolumn{2}{|c|}{ Standing Conditions } \\
\hline & & Means and Resources & Targeted Agencies \\
\hline $\begin{array}{l}\text { LAS CEO, Se- } \\
\text { nior managers }\end{array}$ & $\begin{array}{l}\text { LAS manage- } \\
\text { ment }\end{array}$ & $\begin{array}{l}\text { Authority, discretion on } \\
\text { policies and plans, fi- } \\
\text { nancial resources and } \\
\text { control over financial } \\
\text { and human resources }\end{array}$ & $\begin{array}{l}\text { LAS staff and system } \\
\text { developers }\end{array}$ \\
\hline $\begin{array}{l}\text { Dispatching } \\
\text { personnel and } \\
\text { ambulance } \\
\text { crews }\end{array}$ & LAS staff & $\begin{array}{l}\text { Execution of opera- } \\
\text { tions, discretion on op- } \\
\text { erations, membership } \\
\text { to trade union }\end{array}$ & $\begin{array}{l}\text { LAS management es- } \\
\text { pecially on matters } \\
\text { regarding their jobs }\end{array}$ \\
\hline System Options & $\begin{array}{l}\text { System De- } \\
\text { velopers }\end{array}$ & $\begin{array}{l}\text { Discretion on analysis, } \\
\text { design, development } \\
\text { and technical matters of } \\
\text { the information system }\end{array}$ & $\begin{array}{l}\text { LAS staff in making } \\
\text { them use the system } \\
\text { according to their } \\
\text { specifications and } \\
\text { control over the tech- } \\
\text { nological agents }\end{array}$ \\
\hline
\end{tabular}

The circuit of social integration. This circuit deals with rules of meaning and membership. The CAD system influenced the way employees interpreted management style. The emphasis on spending on technology and the overall LAS autocratic style of management were opposed by LAS unions, who wanted, instead, more training and new vehicles as well as more participation in the process of decision making (ALA 1991). The response managers gave to this position was to push ahead with the CAD system without union participation. Tension rose because the workforce interpreted these moves as a way of undermining the trade unions and concentrating decision making on top management. 


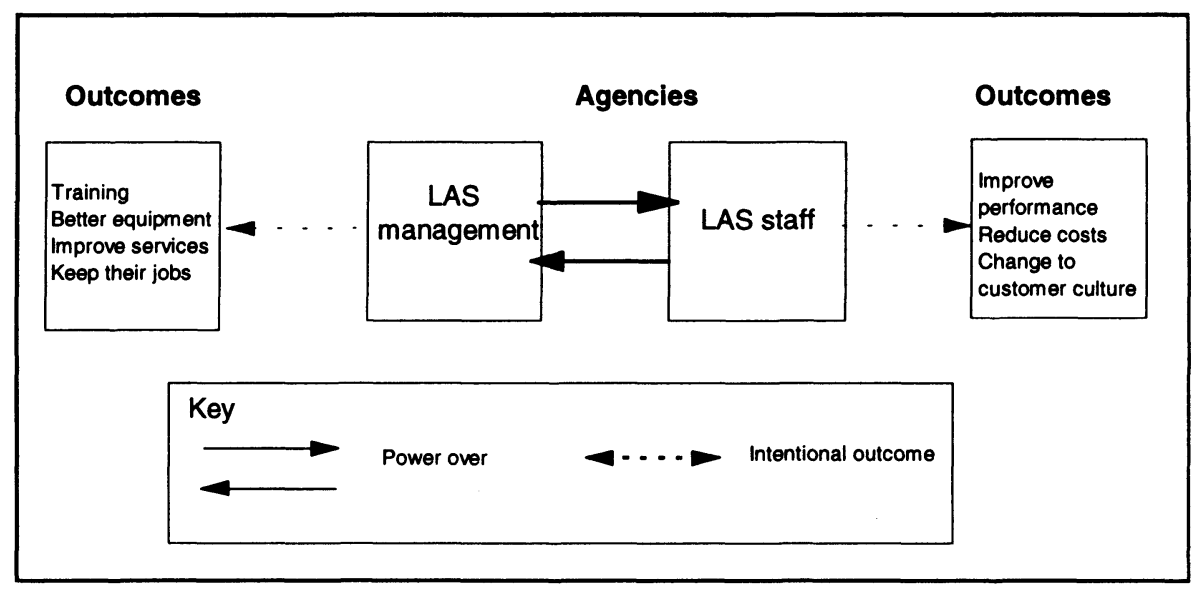

Figure 2 Power Struggle in LAS.

Table 3 The Circuit of Social Integration.

\begin{tabular}{lll}
\hline $\begin{array}{l}\text { Discourse Affecting Rules of } \\
\text { Meaning and Membership }\end{array}$ & \multicolumn{1}{c}{ LAS Management } & \multicolumn{1}{c}{ LAS Staff } \\
\hline $\begin{array}{l}\text { "LAS do not comply with } \\
\text { national standards" }\end{array}$ & $\begin{array}{l}\text { We need a new } \\
\text { information system } \\
\text { and new organiza- } \\
\text { tional culture. }\end{array}$ & $\begin{array}{l}\text { More training and } \\
\text { better equipment. } \\
\text { Better work conditions } \\
\text { would im-prove } \\
\text { performance. }\end{array}$ \\
\hline $\begin{array}{l}\text { "Introducing a new information } \\
\text { systems" }\end{array}$ & $\begin{array}{l}\text { The system will im- } \\
\text { prove services and } \\
\text { increase control } \\
\text { over operations. } \\
\text { Part of strategy to } \\
\text { change culture. }\end{array}$ & $\begin{array}{l}\text { Resources should be } \\
\text { oriented to training and } \\
\text { better equipment. Con- } \\
\text { centrate control of op- } \\
\text { erations on senior man- } \\
\text { agement. Weaken trade } \\
\text { unions }\end{array}$ \\
\hline $\begin{array}{lll}\text { "Despite opposition and criti- } \\
\text { cism management decides to } \\
\text { move forward with the new sys- } \\
\text { tem" }\end{array}$ & $\begin{array}{l}\text { Trade unions do not } \\
\text { co-operate. Intro- } \\
\text { ducing the new sys- } \\
\text { tem is crucial to } \\
\text { achieve managerial } \\
\text { objectives. }\end{array}$ & $\begin{array}{l}\text { Maverick style of man- } \\
\text { agement. }\end{array}$ \\
\hline & & \\
\hline
\end{tabular}


If workers interpreted the system as a threat to their identity and the existence of workers' organizations, managers interpreted workers' attitudes, actions and statements as a lack of collaboration and resistance. This added more pressure to managers, who instead of stopping and reflecting, surrendered to time pressure and decided to go ahead with the project. Resistance was outflanked by managers deploying their resources: money and authority for decision making. The new system reinforced the worsening industrial relations. Workers' attitudes might have only confirmed the belief of managers that the staff was the problem in LAS. Table 3 illustrates the contradictory interpretations of the discourses associated with the introduction of the new CAD information system. These contradictory interpretations hindered social integration, making it difficult for the LAS management to adjust their dispositional power to achieve the institutionalization of the system.

The new information system did not buttress social integration in LAS. The new rules stemming from the new tasks were not translated successfully into the system. Perhaps more importantly, the introduction of the system emphasized the gap and exacerbated relations between management and workers. It is unlikely in an organization, where social integration is low or characterized by conflict, that an information system - particularly if is interpreted as being a weapon of one group against another - can be consolidated and stabilized. In the case of LAS, the system required the total collaboration of the workforce to be successful. Developing and designing information systems needs not only technical but political skills.

The Circuit of System Integration. This circuit concentrates on techniques of control, discipline, and production. The major effect on control and discipline was found in the fact that discretion over deployment of ambulances was taken from the controllers and programmed into the new information system. Ambulances no longer responded to the judgement of controllers but to the calculations and orders produced by an information system. There were changes in the way tasks were classified and distributed. Before the introduction of the system, there were three divisions for dispatching ambulances: north-east, north-west, and south. Each of these divisions was managed by controllers who had a good knowledge of their section, in the sense that they knew those areas of London very well. This personal knowledge allowed them to identify, for example, when an accident was being reported twice. Thus, controllers would not send more than one ambulance to the same place. The inability of the CAD system to identify duplicate reports and the practice of sending more than one ambulance to the same incident was one of the reasons for the collapse in 1992. The design of the CAD system joined the three divisions and included rules for dispatching ambulances, so that the job of the controller, once the system was in place, was made redundant. The information system introduced new tasks and therefore new rules. These rules should have been translated effectively into the IS. The procedures and rules of calculation were introduced by information systems developers who apparently failed to capture the judgments and skills of the controllers. This inability of the system developers was one of the causes for the failure of the system. Table 4 shows the disruption caused to system integration by the new 
CAD system. The organizational measures that accompanied the system, such as the elimination of the three geographical divisions and the substitution of the dispatchers, triggered those disruptions. In this table, we have highlighted the empowerment and disempowerment of agencies. It is not surprising that LAS staff perceived the CAD system as disempowering because it undermined their control over operations.

Table 4 The Circuit of System Integration.

\begin{tabular}{lll}
\hline $\begin{array}{c}\text { Innovations in } \\
\text { Techniques of Control } \\
\text { and Production }\end{array}$ & \multicolumn{1}{c}{ Empowered } & \multicolumn{1}{c}{ Agencies } \\
\hline New information systems & $\begin{array}{l}\text { LAS management in- } \\
\text { creased control of opera- } \\
\text { tions. System options } \\
\text { won the contract. }\end{array}$ & $\begin{array}{l}\text { LAS staff lost control } \\
\text { over operations }\end{array}$ \\
\hline $\begin{array}{l}\text { Replacement of ambu- } \\
\text { lance dispatchers }\end{array}$ & $\begin{array}{l}\text { LAS management have } \\
\text { more money for other } \\
\text { plans. Weaken trade un- }\end{array}$ & $\begin{array}{l}\text { LAde dispatchers were } \\
\text { staff morale went down. }\end{array}$ \\
\hline $\begin{array}{l}\text { Elimination of } \\
\text { geographic divisions }\end{array}$ & [This did not empower \\
& anybody] & $\begin{array}{l}\text { New system operators did } \\
\text { not have control over dis- } \\
\text { patches. }\end{array}$ \\
\hline
\end{tabular}

The system replaced paper records and was installed without magnetic or paper backups (Robinson 1994). It was perhaps the time pressure and the lack of adequate supervision that made managers and system analysts overlook this elementary necessity. There is also evidence that training was not conducted properly. This was critical because the changes introduced were radical, especially in the way ambulances were dispatched and because staff of the central ambulances control were not well trained. For example, assistants and operators of the system were not taught how to cope with more than expected exception calls, a serious error in any system, unforgivable in a system on which people's life may depend.

Obligatory Passage Point. Obligatory passage points are actor networks linked by pieces of discourse whereby organizations translate the circuits of social and system integration in order to achieve outcomes. In the present case, the most evident and important obligatory passage point was the $\mathrm{CAD}$ information system. The CAD was an obligatory passage point linking and translating different actors such as management, market ideas, efficiency expectations, staff expertise, users, systems analysts and patients. If all these actors are translated successfully and their associations remain stable, then the obligatory passage point might be considered successful. 
If all actors had remained faithful to their identities, alliances, and translations, then management would have achieved their objectives. The political atmosphere prevailing in the British government, pushing the NHS to an internal market, was represented in a system that was developed aiming at efficiency. The internal market ideology was translated into techniques and strategies enacted, in this case, by the managers of LAS. Staff expertise was inscribed in the system in the form of rules for allocation and dispatch of ambulances. Users of the system were also translated into the CAD. These translations were represented in the way system developers expected users to operate the system. For example, Mike Smith, Systems Director of LAS, said that the failure of the system was due to users not following the computer system instructions (Daily Telegraph 1992). Decisions made by systems analysts were inscribed into the system in other ways. Managers of LAS considered information technology to be fundamental in achieving the efficiency goals set when they were appointed. This consideration implies the belief that technology is a black box that can be safely left to expert technicians. System analysts were supposed to translate technology into the system in such a way that technology would do what it was told to do. In this sense, systems analysts were allegedly the representatives of information technology. The failure of November 4, 1992, was the result of a mistake: a programmer forgot to activate a routine that would maintain the memory of the system. Thus, designers and developers, the very representatives of technology, were "betrayed" by the technology itself. Poor translation also involved ambulance callers. One of the reasons given for the failure of the system was the excessive amount of exception phone calls. Ambulance requests did not traverse the OPP in expected ways. During that infamous night in October, 1992, LAS headquarters were flooded with 600 unexpected phone calls.

We might conclude that the translation of the actors in the obligatory passage point, the CAD system, failed. This might explain why, despite the fact that management had the power in terms of money and decision making, they failed to achieve their desired outcomes. If we recall Foucault's claimed characteristic of power, which is that power can be recognized in actions, we could say that successful outcomes through the use of technology can only be achieved by successful processes of translations. Successful translation will depend, then, on how faithful actors are toward their definition and their alliances.

\section{CONCLUSIONS}

In this case, successful translations would have been the result of managers reformulating strategies to create a common acceptable meaning for the new system. Furthermore, the project coordinator and LAS management should have identified exactly how the new system was to affect the way job processes and the tasks had been performed before the introduction of the system. 
LAS management considered prematurely the information system as a black box with clearly defined inputs and outputs before it was institutionalized. The inputs were technology and financial and human resources, while the outputs were cultural change and improved performance. There is no doubt about the abject failure of this information system to alter the power structures of the LAS. We have applied the circuits of power framework and demonstrated that the system was a result of strategies and techniques prevailing in the government and within the organization. This analysis illustrates how the framework can shed light on the links between power and information systems. Perhaps more importantly it shows how risky it is to prematurely consider information systems as black boxes producing outputs, such as change in culture and power structures, without considering the social and system integration. ${ }^{6}$

The institutionalization of information systems, although desirable, requires great efforts from organizations, and it depends on many factors. The circuits of power framework is an attempt to encompass those factors in a theoretical model. The framework we have suggested could be useful for researchers interested in the political dimensions of information systems or in the processes of institutionalization in identifying those variables where collecting data is required. Furthermore, it can help researchers in analyzing and interpreting the data. Practitioners of information systems, either analysts or managers, can benefit from the framework and the example presented here when understanding their own systems in their own circumstances. The validity of an interpretive theory is difficult to establish. As Walsham (1993, p. 6) declares, "in the interpretive tradition, there are no correct and incorrect theories but there are interesting and less interesting ways to view the world." We hope the theoretical framework proposed here and the way we have applied it will be of interest to our readers and that the insights presented can serve the intersubjective process of theory building.

\section{REFERENCES}

Akrich, M. (1992). "The De-scription of Technical Objects." In W. E. Bijker and J. Law (Editors), Shaping Technology/Building Society. Cambridge, Massachusetts: MIT Press, pp. 205-224.

${ }^{6} \mathrm{We}$ would like to pick up the point we made above about Collins and Yearly's critique of actor network theory. They also criticize actor network theory in the sense that tacit human knowledge cannot be translated onto nonhuman actors, i.e., actants. We believe that the disaster of the LAS information system shows the failure of information systems analysts and programmers in their attempts to inscribe on the system the tacit knowledge of the ambulance dispatchers. 
Akrich, M., and Latour, B. (1992). “A Summary of a Convenient Vocabulary for the Semiotics of Human and Nonhuman Assemblies." In W. E. Bijker and J. Law (Editors), Shaping Technology/Building Society. Cambridge, Massachusetts: MIT Press, pp. 259-264.

ALA (1991). London Ambulances: A Service in Crisis. Pamphlet No. ALA, Association of London Authorities.

Berger, P., and Luckman, T. (1967). The Social Construction of Reality: A Treatise in the Sociology of Knowledge. London: Penguin Books.

Beynon-Davies, P. (1993). The London Ambulance Service's Computerised Dispatch System: A Case Study in Information Systems Failure. University of Glamorgan Pontyprid.

Bjerknes, G.; Ehn, P.. and Kyng, M. (Editors) (1987). Computers and Democracy: A Scandinavian Challenge. Aldershot, England: Avebury.

Bloomfield, B. P. (1990).

Bloomfield, B. P., and Best, A. (1992). "Management Consultants: Systems Development, Power and the Translation of Problems." The Sociological Review, Volume 40, Number 3, pp. 533-560.

Bloomfield, B. P., and Coombs, R. (1992). "Information Technology, Control and Power: The Centralization and Decentralization Debate Revisited." Journal of Management Studies, Volume 29, Number 4, pp. 459-484.

Bloomfield, B. P., and Danieli, A. (1995). "The Role of Management Consultants in The Development of Information Technology: The Indissoluble Nature of Socio-Political and Technical Skills. Journal of Management Studies, Volume 32, Number 1, pp. 23-46.

Bloomfield, B. P., and McLean, C. (1995). "Madness and Organization: Informed Management and Empowerment." In W. J. Orlikowski, G. Walsham, M. R. Jones, and J. I. DeGross (Editors), Information Technology and Changes in Organizational Work. London: Chapman and Hall, pp. 371-392.

Bodker, S.; Ehn, P.; Kyng, M.; Kammersgaard, J.; and Sundblad, Y. (1987). “A Utopian Experience: On Design of Powerful Computer-Based Tools for Skilled Graphic Workers." In G. Bjerknes, P. Ehn, and M. Kyng (Editors), Computer and Democracy: A Scandinavian Challenge. Aldershot, England: Avebury, pp. 251278.

Callon, M. (1986). "Some Elements of a Sociology of Translation: Domestication of the Scallops and the Fishermen of St. Brieuc Bay." In J. Law (Editor), Power, Action and Belief. London: Routledge and Kegan Paul, pp. 196-233.

Callon, M. (1991). "Techno-Economic Networks and Irreversibility." In J. Law (Editor), A Sociology of Monsters: Essays on Power, Technology and Domination. London: Routledge, pp. 132-161.

Callon, M., and Latour, B. (1992). "Don't Throw the Baby Out with the Bath School! A Reply to Collins and Yearley." In A. Pickering (Editor), Science as Practice and Culture. Chicago: The University of Chicago Press, pp. 343-368. 
Callon, M.; Law, J.; and Rip, A. (Editors) (1986). Mapping the Dynamics of Science and Technology: Sociology of Science in the Real World. London: The Macmillan Press Ltd.

Clegg, S. R. (1989). Frameworks of Power. London: Sage Publications.

Clegg, S. R. (1990). Modern Organizations: Organization Studies in the Postmodern World. London: Sage Publications.

Collins, H. M., and Yearley, S. (1992a). "Epistemological Chicken." In A. Pickering (Editor), Science as Practice and Culture. Chicago: The University of Chicago Press, pp. 301-326.

Collins, H. M., and Yearley, S. (1992b). "Journey Into Space." In A. Pickering (Editor), Science as Practice and Culture. Chicago: The University of Chicago Press, pp. 369-389.

Dahl, R. (1957). "The Concept of Power." Behavioral Science, Volume 2, pp. 201105.

Daily Telegraph, 29 October 1992.

Dimaggio, P., and Powell, W. (1983). "Institutional Isomorphism and Collective Rationality in Organization Fields." American Sociological Review, Volume 48, Number 2, pp. 147-160.

DiMaggio, P. J., and Powell, W. W. (1991a). "The Iron Cage Revisited: Institutional Isomorphism and Collective Rationality in Organizational Fields." In W. W. Powell and P. J. DiMaggio (Editors), The New Institutionalism in Organizational Analysis. Chicago: The University of Chicago Press, pp. 63-82.

Ehn, P., and Kyng, M. (1987). "The Collective Resource Approach to Systems Design.” In P. Ehn and M. Kyng (Editors), Computers and Democracy. Aldershot, England: Avebury, pp. 17-57.

Foucault, M. (1972). The Archaeology of Knowledge. London: Tavistock.

Foucault, M. (1977). Discipline and Punish. New York: Vintage Books.

Foucault, M. (1980). Power/Knowledge: Selected Interviews and Other Writings 1972-77. Brighton: Harvester Press.

Friedman, A., and Cornford, D. (1987). "Strategies for Meeting User Demands: An International Perspective." In G. Bjerknes, P. Ehn, and M. Kyng (Editors), Computers and Democracy: A Scandinavian Challenge. Aldershot, England: Avebury, pp. 137-162.

Giddens, A. (1979). Central Problems in Social Theory. London: Macmillan.

Giddens, A. (1984). The Constitution of Society. Cambridge, England: Polity Press.

Habermas, J. (1970). "Towards a Theory of Communicative Competence." Inquiry, Volume 13, pp. 360-375.

Habermas, J. (1972). Knowledge and Human Interests (J. Shapiro, Translator). Boston: Beacon Press.

Habermas, J. (1979). Communication and the Evolution of Society (T. McCarthy, Translator). Boston: Beacon Press. 
Hickson, D. J.; Higgins, C. R.; Less, C. A.; Schneck, R. E.; and Pennings, J. M. A. (1971). "A Strategic Contingencies Theory of Intraorganizational Power." Administrative Science Quarterly, Volume 16, Number 2, pp. 216-229.

Hirschheim, R., and Klein, H. K. (1994). "Realizing Emancipatory Principles in Information Systems Development: The Case for ETHICS." MIS Quarterly, March, pp. 83-109.

Hougham, M. G. (1995). London Ambulance Service (Project Management Case Study No. PM696). Henley Management College.

Jarvenpaa, S. L. (1991). "Panning for Gold in Information Systems Research: 'Second-Hand' Data." In H.-E. Nissen, H. K. Klein, and R. Hirschheim (Editors), Information Systems Research: Contemporary Approaches and Emergent Traditions. Amsterdam: North Holland, pp. 63-80.

Keen, P. G. W. (1981). "Information Systems and Organizational Change." Сотmunications of the ACM, Volume 24, Number 1, pp. 24-33.

Latour, B. (1987). Science in Action. Cambridge, Massachusetts: Harvard University Press.

Latour, B. (1991). "Technology is Society Made Durable." In J. Law (Editor), A Sociology of Monsters: Essays on Power, Technology and Domination. London: Routledge, pp. 103-131.

Law, J. (Editor) (1986). Power, Action and Belief: A New Sociology of Knowledge? London: Routledge and Kegan Paul.

Law, J. (1991a). "Power, Discretion and Strategy." In J. Law (Editor), A Sociology of Monsters: Essays on Power, Technology and Domination. London: Routledge, pp. 165-191.

Law, J. (Editor) (1991b). A Sociology of Monsters: Essays on Power, Technology and Domination. London: Routledge.

Lockwood, D. (1964). "Social Integration and System Integration." In G. K. Zollschan and W. Hirsch (Editors), Explorations in Social Change. London: Routledge and Kegan Paul, pp. 244-257.

Lukes, S. (1974). Power: A Radical View. London: The Macmillan Press Ltd.

Markus, M. L. (1983). "Power, Politics, and MIS Implementation." Communications of the ACM, Volume 26, Number 6, pp. 430-444.

Markus, M. L., and Bjørn-Andersen, N. (1987). "Power Over Users: Its Exercise by System Professionals." Communications of the ACM, Volume 30, Number 6, pp. 498-504.

Meyer, J., and Rowan, B. (1991). "Institutionalized Organizations: Formal Structure as Myth and Ceremony." In W. W. Powell and P. J. DiMaggio (Editors), The New Institutionalism in Organizational Analysis. Chicago: The University Press of Chicago, pp. 41-62.

Mintzberg, H. (1983). Power In and Around Organizations. Englewood Cliffs, New Jersey: Prentice Hall.

Monteiro, E., and Hanseth, O. (1995). "Social Shaping of Information Infrastructure: On Being Specific About the Technology.” In W. J. Orlikowski, G. Walsham, M. 
R. Jones, and J. I. DeGross (Editors), Information Technology and Changes in

Organizational Work. London: Chapman and Hall, pp. 325-243.

NUPE (1992). Ambulance Alert - A NUPE Report.

Orlikowski, W., and Robey, D. (1991). "Information Technology and the Structuring of Organizations." Information Systems Research, Volume 2, Number 2, pp. 143169.

Page, D.; Williams, P.; and Boyd, D. (1993). Report of the Public Inquiry into the London Ambulance Service. HMSO.

Pfeffer, J. (1981). Power in Organizations. Marshfield, Massachusetts: Pitman.

Robinson, B. (1994). 'And Treat Those Two Imposters Just The Same': Analysing Systems Failure as a Social Process. Information Technology Institute, University of Salford.

Sewell, G., and Wilkinson, B. (1992). "'Someone to Watch Over Me': Surveillance, Discipline and the Just-In-Time Labor Process." Sociology, Volume 2, Number 6, 271-289.

Vidgen, R., and McMaster, T. (1995). "Black Boxes, Non-Human Stakeholders and the Translation of IT Trough Mediation.” In W. J. Orlikowski, G. Walsham, M. R. Jones, and J. I. DeGross (Editors), Information Technology and Changes in Organizational Work. London: Chapman and Hall, pp. 250-271.

Walsham, G. (1993). Interpreting Information Systems in Organizations. Chichester, England: John Wiley.

Zuboff, S. (1988). In the Age of the Smart Machine. New York: Basic Books.

\section{BIOGRAPHY}

Leister Silva is a Ph.D. student in the Department of Information Systems at the London School of Economics and Political Science. He has coordinated several software and information systems projects for a research center of the Pan-American Health Organization. He has also worked for the same organization as an Information Systems consultant for the American region. His current research at the LSE is focused on the relationship between power and information systems in organizations. One of the objectives of this research is to develop a theoretical framework that would help to identify the relevant elements of the power phenomenon regarding information systems.

James Backhouse teaches in the Information Systems Department of the London School of Economics and Political Science (LSE). He writes widely for academic and commercial publications, advises international clients, and is consulting editor for a number of journals, including Journal of Financial Crime. A particular theme in his work has been the emphasis on understanding the role of semantics in communications and information, and his thesis refined an analytical tool, semantic analysis, 
which supports management and systems development activities. Since 1992, his research interests have extended to the field of information security, and he is now the Director of the LSE Computer Security Research Centre. The Centre focuses on the study of organizational and management aspects of the security and privacy of information systems. 